\title{
Knowledge, attitudes, and practices of primary health care physicians regarding the pre-travel counselling of patients with type 2 diabetes in Riyadh, Saudi Arabia
}

\author{
Rabia Khalid Alduraibi ${ }^{1,2^{*}}$ (D), Turky H. Almigbal ${ }^{3}$,Abdullah A. Alrasheed ${ }^{3}$ and Mohammed Ali Batais ${ }^{3}$
}

\begin{abstract}
Background: Travel has become an integral part of Saudi life. People with diabetes face many challenges while travelling that can have detrimental effects on glycaemic control. However, no previous studies have investigated pre-travel counselling in Saudi Arabia. This study aims to assess the knowledge, attitudes and practices of primary health care (PHC) physicians regarding pre-travel counselling for patients with type 2 diabetes.

Methods: This cross-sectional study was conducted in PHC centres under the Ministry of Health in Riyadh, Saudi Arabia, during the period 2018-2019. A cluster multistage random sampling technique was used to recruit physicians. The data were collected through a self-administered questionnaire.

Results: Three hundred and eighty-five primary health care physicians were recruited. This study showed that more than half (57.9\%) of PHC physicians had poor knowledge scores. Additionally, the following characteristics were significantly associated with poor knowledge: being younger in age, being male, being Saudi, being a general practitioner, and having limited (0-5 years) experience. A total of 183 (47.5\%) subjects showed disagreement attitudes towards the importance of pre-travel counselling among patients with diabetes. Furthermore, these disagreement attitudes were significantly associated with being older and having more years of experience. The majority (62.6\%) of the physicians had poor practice scores. Poor practices were detected among physicians who were younger, male, and Saudi and who had a general practitioner specialty and degree.

Conclusions: It could be concluded that a gap was detected in the knowledge and practices of primary health care physicians regarding pre-travel counselling for people with type 2 diabetes. Therefore, it is necessary to create easily accessible travel medicine education programmes for Saudi PHC providers to improve the management of travellers with diabetes.
\end{abstract}

Keywords: Knowledge, Attitude, Diabetes, Pre-travel counselling, Saudi traveller

\footnotetext{
* Correspondence: Ralduraibi@gmail.com

1 King Fahad Specialist Hospital, Buraydah, Saudi Arabia

2Department of Family and Community Medicine, King Khalid University

Hospital, Box 2925, Riyadh, PO 11461, Saudi Arabia

Full list of author information is available at the end of the article
}

C C The Author(s). 2020 Open Access This article is licensed under a Creative Commons Attribution 4.0 International License, which permits use, sharing, adaptation, distribution and reproduction in any medium or format, as long as you give appropriate credit to the original author(s) and the source, provide a link to the Creative Commons licence, and indicate if changes were made. The images or other third party material in this article are included in the article's Creative Commons licence, unless indicated otherwise in a credit line to the material. If material is not included in the article's Creative Commons licence and your intended use is not permitted by statutory regulation or exceeds the permitted use, you will need to obtain permission directly from the copyright holder. To view a copy of this licence, visit http://creativecommons.org/licenses/by/4.0/ The Creative Commons Public Domain Dedication waiver (http://creativecommons.org/publicdomain/zero/1.0/) applies to the data made available in this article, unless otherwise stated in a credit line to the data. 


\section{Background}

Over the last few decades, the number of travellers on international flights has been rising, and the prevalence of travel-acquired illness is likely to rise in proportion to the predicted increase in international travel [1].

Travel has become an integral part of Saudi life. Whether for pleasure or work, millions of Saudis travel outside their country every year. Travelling abroad, especially to a developing country, involves a health risk, and according to international surveys, over half of travellers could face a health problem during or after their trip. Travel places an individual in unfamiliar environments, which can be especially challenging for those with chronic diseases such as diabetes [2, 3].

A number of studies have shown that the choice of travel destination by patients with diabetes may be affected by their use of insulin, and some of those patients avoid international travel altogether because of their disease $[4,5]$.

While travelling, people with diabetes face many challenges that can affect their glycaemic control, including changes in their routines regarding diet and physical activity, and difficulties in adjusting insulin dose and timing after crossing multiple times zones, as well as the risk of infectious diseases, especially when travelling to developing countries $[5,6]$.

Many travellers with diabetes are not aware of this health risk. Therefore, pre-travel advice provided by primary health care (PHC) physicians is important in maintaining travellers' health during their journey. Travel health advice is a critical step in a pre-travel consultation. Unfortunately, the uptake of pre-travel health advice remains low, even though most travel-related health problems can be prevented with high-quality medical consultations that include information on lifestyle and dietary rules or the prescription of appropriate medications $[2,3,6,7]$.

Few published health studies have examined physicians' knowledge and practices regarding travel and diabetes. To the best of our knowledge, no study has focused on travel health practices in Saudi Arabia or even in the Middle East at large. Therefore, our objective is to assess the knowledge and attitudes of PHC physicians regarding pre-travel counselling for patients with type 2 diabetes and to examine the association between the physicians' demographic characteristics and their knowledge and attitudes.

\section{Methods}

\section{Study setting}

A cross-sectional study was conducted using a selfadministered questionnaire among primary health care (PHC) physicians working at primary health care centres (PHCCs) under the Ministry of Health $(\mathrm{MOH})$ in
Riyadh, Saudi Arabia, during the period from September 2018 to March 2019.

According to the database of the General Directorate of Health Affairs in Riyadh, approximately 656 physicians work in 135 PHCCs of the $\mathrm{MOH}$ in the city of Riyadh. All Primary care physicians (PCPs) working in PHCCs under the $\mathrm{MOH}$ in Riyadh were eligible for inclusion. All specialists who were not in direct contact with patients with diabetes, physicians who were on an extended leave of duty, and physicians who declined to participate were excluded.

A cluster multistage random sampling technique was employed. For the purpose of the study, PHCCs were clustered according to the city's geographic divisions into five regions (middle, southern, northern, eastern, and western), with 18-34 PHCCs in each region. Of these PHCCs, 10 PHCCs in each region were randomly chosen. Therefore, 50 PHCCs were included in the study.

\section{Sample size}

The sample size was calculated using a standard sample size equation " $n=\mathrm{z}^{2} \mathrm{p}(1-\mathrm{p}) / \mathrm{e}^{2 \text { " }}$ and an assumed proportion of $50 \%$ (proportion of medical physicians who had correct knowledge regarding pre-travel counselling for patients with diabetes). Using a 95\% confidence interval and a $5 \%$ margin of error, the sample size was estimated to be 385 and was adjusted to 410 to compensate for the non-response rate.

\section{Participants and survey instrument}

All physicians present at the time of data collection in the selected PHCCs were included; hard copies of the questionnaires were delivered to the available physicians. Without seeing it first, the physicians were asked to complete the anonymous self-administered survey in English in order to assess their basic background knowledge.

The self-administered questionnaire was developed by the principal investigator based on the study objectives and after a literature review of similar studies [8-10]. A panel of two diabetologists and one family physician, all of whom provide clinical care for patients with diabetes and are familiar with diabetes guidelines and the survey's development, assessed the questionnaire for appropriateness, accuracy, and relevance and were asked to critique the questionnaire's content. To ensure the face validity of the questionnaire, it was presented to a sample of 20 participants in a pilot study and then finalized. The results of the piloted questionnaires were not included in the analysis.

The questionnaire is divided into four sections with a total of 24 questions. The first section pertains to 
demographic characteristics, including age, gender, level of education, and nationality.

The second section assesses the physicians' knowledge regarding diabetes and travel. The response choices for knowledge items include "yes", "no" and "do not know". Correct answers were scored as 1 , while incorrect answers and "do not know" were scored as 0 . The total knowledge score ranges from 0 to 10 (10 items).

After calculating the knowledge score for each participant, we extracted descriptive statistics and found that the score ranged between 2 as a minimum score and 10 as a maximum score, after that the range was calculated, which is the difference between the highest score and the lowest score $(10-2=8)$, then knowledge levels were classified as follows: from (2 to 5) consider Poor knowledge and from (6 to 8) consider medium level and from (9 to 10) consider high level of knowledge.

The third section assesses the attitudes of physicians towards pre-travel counselling for patients with diabetes. Five-point Likert scale items were used; strongly agree responses were scored as 5 , agree as 4 , uncertain as 3 , disagree as 2 , and strongly disagree as 1 . The total attitudes score ranges from 6 to 30 (6 items), with higher scores indicating a higher degree of agreement. The fourth section assesses the practices of physicians towards pre-travel counselling.

Physicians at or above the mean score were considered to present good knowledge, high attitudes, or optimal practices, while those under the mean score were categorized as showing poor knowledge, low attitudes, or poor practices.

\section{Data management and analysis plan}

Data were coded and entered using the Statistical Package for Social Sciences Version 22 (IBM Corporation, Armonk, NY, USA). Categorical data were presented as numbers and percentages and were analysed using the chi-square test. Knowledge, attitude, and practice (KAP) scores were calculated; scores $\geq 80 \%$ were considered good, scores of $60-<80 \%$ were considered moderate, and scores $<60 \%$ were considered poor. Continuous data were tested for normality by using the Shapiro-Wilk test. Data that were not normally distributed were expressed as medians and interquartile ranges (expressed as 25th75th percentiles). Continuous, non-normally distributed independent data were analysed using the MannWhitney $U$ test, whereas continuous, non-normally distributed paired data were analysed by using Friedman's two-way analysis of variance by ranks. $P \leq 0.05$ was considered statistically significant.

\section{Ethical considerations}

Approval for the study was obtained from the Institutional Review Board, College of Medicine, King Saud
University (no. E-18-0488), Riyadh, Saudi Arabia. Official approval letters were obtained from the Directorate of Health Affairs in Riyadh. Each participant received the questionnaire and was informed about the objective of the present study. All participants provided informed written consent before the completion of the questionnaires. The Institutional Review Board has agreed that completing the questionnaire will imply consent.

\section{Results \\ Sample characteristics}

Three hundred and eighty-five of 410 primary health care physicians completed the questionnaires (response rate of $94 \%)$.

Table 1 shows participants' socio-demographic characteristics. $207(53.8 \%)$ of PCPs were aged $\leq 35$ years, $178(46.2 \%)$ were aged $>35$ years. As the ages had extreme values we chose the age value 35 as a cutoff point as it was the median value. More than half of the participants (56.4\%) were females, and $47.3 \%$ of the participants were Saudi physicians. The participants were either general practitioners $(54.5 \%)$ or family medicine physicians (45.5\%). Most of the respondents were general practitioners and residents (54.5 and $27.8 \%$, respectively), whereas registrars and consultants were less common (16.1 and 1.6\%, respectively). Regarding work experience, the majority (39.7\%) had $0-5$ years of experience, and fewer participants had 6-10 years (19.5\%), $11-15$ years (20\%), or $>15$ years $(20.8 \%)$ of experience.

Table 1 Socio-demographic characteristics

\begin{tabular}{llll}
\hline Categorical variables & & N & $\%$ \\
\hline Age & $\leq 35$ & 207 & $53.8 \%$ \\
Sex & $>35$ & 178 & $46.2 \%$ \\
& Female & 217 & $56.4 \%$ \\
Nationality & Male & 168 & $43.6 \%$ \\
& Non-Saudi & 203 & $52.7 \%$ \\
Specialty & Saudi & 182 & $47.3 \%$ \\
Degree of Education & Family Medicine & 175 & $45.5 \%$ \\
& General Practitioner & 210 & $54.5 \%$ \\
& General Practitioner & 210 & $54.5 \%$ \\
& Resident & 107 & $27.8 \%$ \\
& Register & 62 & $16.1 \%$ \\
Years of Practice & Consultant & 6 & $1.6 \%$ \\
& $0-5$ & 153 & $39.7 \%$ \\
& $6-10$ & 75 & $19.5 \%$ \\
& $11-15$ & 77 & $20.0 \%$ \\
& $>15$ & 80 & $20.8 \%$ \\
\hline
\end{tabular}




\section{Knowledge of diabetes and travel}

The majority (96.4\%) of PCPs had adequate knowledge that patients with diabetes should be advised to carry medicines and carbohydrate-rich snacks in easily accessible bags while travelling. In contrast, only twothirds (60.8\%) knew that insulin should not be stored in checked luggage. Moreover, more than half of physicians $(56.9 \%)$ did not know that travelling across more than five time zones requires adjustment of insulin dose and frequency, while only approximately one third (32.2\%) knew that travelling across more than five time zones does not require adjustment of oral anti-hypoglycaemic dose. Few PCPs knew that patients with diabetes travelling to the east region may need to increase their insulin dose, while those travelling to the west region may need to decrease their insulin dose (6.8 and $6.2 \%$, respectively). A total of 212 (55.1\%) physicians were aware of the effect of hot or cold climates on insulin and blood glucose monitoring while travelling. The majority $(96.6 \%)$ recognized the importance of pre-travel vaccination, and all PCPs realized that patients with diabetes need to carry their diabetes ID while travelling abroad. Participants' knowledge was deficient regarding the need to avoid injecting insulin while a plane is taking off (26.2\%) (Table 2).

The total knowledge score ranged from 2 to 10 , with a median of $5(\mathrm{IQR}=4-6)$. More than half $(57.9 \%)$ of the participants had poor scores, and 3.6\% had good scores. Table 3 demonstrates a statistically significant association between the total knowledge score and age, sex, nationality, level of education and years of experience. Practitioners' nationality had strongly significant association with knowledge regarding diabetes and travel; since 130 out of 180 Non-Saudi which represents (72.22\%) of Non-Saudi physicians had poor knowledge regarding diabetes and travel verses only 93 out of 203 Saudi physicians which represents $(45.81 \%)$ of Saudi physicians. Significant associations were found $(P<.05)$ between poor knowledge and the following participant characteristics: being younger than 35 years old, being male, being Saudi, being a general practitioner and having limited ( $0-5$ years) experience.

\section{Physicians' attitudes towards pre-travel counselling and diabetes}

The participants' attitudes towards pre-travel counselling are illustrated in Table 4. Most of them strongly agreed with the following statements: pre-travel counselling for patients with diabetes is important; the availability of an Arabic resource to increase patients' awareness of health practices before, during and after the trip is needed; and I would advise patients to visit such a resource (90.4, 83.4, and $83.9 \%$, respectively). Moreover, the majority (77.7\%) of PCPs strongly agreed that seeking medical advice before travelling would decrease patients' chances of getting sick during their trip. Furthermore, more than half (57.1\%) strongly agreed that Saudi Arabia lacks travel medicine practices, and two-thirds (60\%) strongly agreed that our society lacks knowledge of the importance of travel medicine.

The total attitudes score ranged from 0 to 6 with a median of 5 (IQR $=4-6)$. More than half $(52.5 \%)$ of the participants had strong agreement attitudes, while $183(47.5 \%)$ showed disagreement attitudes towards the importance of pre-travel counselling among patients with diabetes. Table 5 shows that significantly higher percentages of physicians with disagreement attitudes were older than 35 years, whereas most participants who showed agreement were younger $(p=.003)$. In addition, years of experience were significantly higher among physicians with disagreement attitudes $(p=.006)$.

Table 2 Practitioners' knowledge of pre-travel counselling ( $N=385)$

\begin{tabular}{|c|c|c|}
\hline Question & $\mathbf{N}$ & $\%$ \\
\hline $\begin{array}{l}\text { 1- Correctly answered that patients with diabetes should be advised to carry medicines and carbohydrate-rich snacks in easily access- } \\
\text { ible bags while travelling }\end{array}$ & 371 & $96.4 \%$ \\
\hline 2- Correctly answered that insulin cannot be stored in checked luggage. & 234 & $60.8 \%$ \\
\hline 3- Correctly answered that, during air travel, patients with diabetes are advised to not inject insulin at take-off. & 101 & $26.2 \%$ \\
\hline 4- Correctly answered that travelling across more than five time zones requires adjustment of insulin dose and frequency. & 166 & $43.1 \%$ \\
\hline 5- Correctly answered that travelling across more than five time zones does not require adjustment of oral anti-hypoglycaemic dose. & 124 & $32.2 \%$ \\
\hline 6- Correctly answered that patients with diabetes who are travelling to the east region may need to increase their insulin dose & 26 & $6.8 \%$ \\
\hline 7- Correctly answered that patients with diabetes who are travelling to the west region may need to decrease their insulin dose. & 24 & $6.2 \%$ \\
\hline $\begin{array}{l}\text { 8- Correctly answered that extremes of hot or cold climates can affect insulin and blood glucose monitoring in patients with diabetes } \\
\text { while travelling. }\end{array}$ & 212 & $55.1 \%$ \\
\hline 9- Correctly answered that pre-travel vaccination is important for patients with diabetes. & 372 & $96.6 \%$ \\
\hline 10- Correctly answered that patients with diabetes need to carry ID that says that they have diabetes while travelling abroad. & 385 & $100.0 \%$ \\
\hline
\end{tabular}


Table 3 Association between knowledge score and socio-demographic data

\begin{tabular}{|c|c|c|c|c|c|c|c|c|c|c|}
\hline & & \multicolumn{8}{|c|}{ Knowledge Score } & \multirow{3}{*}{$\begin{array}{l}\text { Chi-Square Test } \\
P \text { value }\end{array}$} \\
\hline & & \multicolumn{2}{|c|}{$\begin{array}{l}\text { Good } \\
N=14 \text { (3.6\%) }\end{array}$} & \multicolumn{2}{|c|}{$\begin{array}{l}\text { Moderate } \\
N=148(38.4 \%)\end{array}$} & \multicolumn{2}{|c|}{$\begin{array}{l}\text { Poor } \\
N=223(57.9 \%)\end{array}$} & \multicolumn{2}{|c|}{$\begin{array}{l}\text { Total } \\
N=385\end{array}$} & \\
\hline & & $\mathrm{N}$ & $\%$ & $\mathrm{~N}$ & $\%$ & $\mathrm{~N}$ & $\%$ & $\mathrm{~N}$ & $\%$ & \\
\hline \multirow[t]{2}{*}{ Age } & $\leq 35$ & 2 & $14.3 \%$ & 61 & $41.2 \%$ & 144 & $64.6 \%$ & 207 & $53.8 \%$ & $<.001^{*}$ \\
\hline & $>35$ & 12 & $85.7 \%$ & 87 & $58.8 \%$ & 79 & $35.4 \%$ & 178 & $46.2 \%$ & \\
\hline \multirow[t]{2}{*}{ Sex } & Female & 8 & $57.1 \%$ & 99 & $66.9 \%$ & 110 & $49.3 \%$ & 217 & $56.4 \%$ & $.004^{*}$ \\
\hline & Male & 6 & $42.9 \%$ & 49 & $33.1 \%$ & 113 & $50.7 \%$ & 168 & $43.6 \%$ & \\
\hline \multirow[t]{2}{*}{ Nationality } & Non-Saudi & 12 & $85.7 \%$ & 98 & $66.2 \%$ & 93 & $41.7 \%$ & 203 & $52.7 \%$ & $<.001^{*}$ \\
\hline & Saudi & 2 & $14.3 \%$ & 50 & $33.8 \%$ & 130 & $58.3 \%$ & 182 & $47.3 \%$ & \\
\hline \multirow[t]{2}{*}{ Specialty } & Family Medicine & 4 & $28.6 \%$ & 59 & $39.9 \%$ & 112 & $50.2 \%$ & 175 & $45.5 \%$ & .063 \\
\hline & General Practitioner & 10 & $71.4 \%$ & 89 & $60.1 \%$ & 111 & $49.8 \%$ & 210 & $54.5 \%$ & \\
\hline \multirow[t]{4}{*}{ Education Degree } & General Practitioner & 10 & $71.4 \%$ & 89 & $60.1 \%$ & 111 & $49.8 \%$ & 210 & $54.5 \%$ & $<.001^{*}$ \\
\hline & Resident & 2 & $14.3 \%$ & 23 & $15.5 \%$ & 82 & $36.8 \%$ & 107 & $27.8 \%$ & \\
\hline & Register & 2 & $14.3 \%$ & 34 & $23.0 \%$ & 26 & $11.7 \%$ & 62 & $16.1 \%$ & \\
\hline & Consultant & 0 & $0.0 \%$ & 2 & $1.4 \%$ & 4 & $1.8 \%$ & 6 & $1.6 \%$ & \\
\hline \multirow[t]{4}{*}{ Years of Practice } & $0-5$ & 2 & $14.3 \%$ & 42 & $28.4 \%$ & 109 & $48.9 \%$ & 153 & $39.7 \%$ & $<.001^{*}$ \\
\hline & $6-10$ & 0 & $0.0 \%$ & 25 & $16.9 \%$ & 50 & $22.4 \%$ & 75 & $19.5 \%$ & \\
\hline & $11-15$ & 4 & $28.6 \%$ & 36 & $24.3 \%$ & 37 & $16.6 \%$ & 77 & $20.0 \%$ & \\
\hline & $>15$ & 8 & $57.1 \%$ & 45 & $30.4 \%$ & 27 & $12.1 \%$ & 80 & $20.8 \%$ & \\
\hline
\end{tabular}

*significant at $p<.05$

\section{Management practices}

The relationship between physicians' practices towards pre-travel counselling and their degree of education is illustrated in Table 6 . The majority (46.5\%) of the participants reported that 20-40 patients with diabetes visit the clinic weekly for any reason. However, approximately $53 \%$ reported that only $1-10$ patients per month ask for advice before travelling; this number was significantly increased among general practitioners $(p<.001)$. Two hundred and thirty $(59.7 \%)$ participants reported that pre-travel counselling would take 5-15 min. A significantly higher percentage of

Table 4 Practitioners' attitudes towards pre-travel counselling $(N=385)$

\begin{tabular}{|c|c|c|c|}
\hline Question & & $\mathbf{N}$ & $\%$ \\
\hline \multirow[t]{2}{*}{ 1- Pre-travel counselling for patients with diabetes is important. } & Agree & 37 & $9.6 \%$ \\
\hline & $\begin{array}{l}\text { Strongly } \\
\text { agree }\end{array}$ & 348 & $90.4 \%$ \\
\hline \multirow{2}{*}{$\begin{array}{l}\text { 2- The availability of an Arabic resource to increase patients' awareness of health practices before, during and after the trip } \\
\text { is needed. }\end{array}$} & Agree & 64 & $16.6 \%$ \\
\hline & $\begin{array}{l}\text { Strongly } \\
\text { agree }\end{array}$ & 321 & $83.4 \%$ \\
\hline \multirow{2}{*}{$\begin{array}{l}\text { 3- If there is a trusted Arabic resource to increase patients' awareness of health practices before, during and after the trip, I } \\
\text { will advise my patient to visit it. }\end{array}$} & Agree & 62 & $16.1 \%$ \\
\hline & $\begin{array}{l}\text { Strongly } \\
\text { agree }\end{array}$ & 323 & $83.9 \%$ \\
\hline \multirow[t]{2}{*}{ 4- Patients who seek medical advice before travelling will have lower chances of getting sick during their trip. } & Agree & 86 & $22.3 \%$ \\
\hline & $\begin{array}{l}\text { Strongly } \\
\text { agree }\end{array}$ & 299 & $77.7 \%$ \\
\hline \multirow[t]{2}{*}{ 5- In Saudi Arabia, we lack the practice of travel medicine. } & Agree & 159 & $41.3 \%$ \\
\hline & $\begin{array}{l}\text { Strongly } \\
\text { agree }\end{array}$ & 220 & $57.1 \%$ \\
\hline \multirow[t]{2}{*}{ 6- Our society lacks knowledge of the importance of travel medicine. } & Agree & 146 & $37.9 \%$ \\
\hline & $\begin{array}{l}\text { Strongly } \\
\text { agree }\end{array}$ & 231 & $60.0 \%$ \\
\hline
\end{tabular}


Table 5 Association between attitudes score and socio-demographic data

\begin{tabular}{|c|c|c|c|c|c|c|c|c|}
\hline & & \multicolumn{6}{|c|}{ Attitudes score } & \multirow[b]{3}{*}{$P$ value } \\
\hline & & \multicolumn{2}{|c|}{$\begin{array}{l}\text { Disagree } \\
N=183(47.5 \%)\end{array}$} & \multicolumn{2}{|c|}{$\begin{array}{l}\text { Agree } \\
N=202(52.5 \%)\end{array}$} & \multicolumn{2}{|c|}{$\begin{array}{l}\text { Total } \\
N=385\end{array}$} & \\
\hline & & $\mathrm{N}$ & $\%$ & $\mathrm{~N}$ & $\%$ & $\mathbf{N}$ & $\%$ & \\
\hline \multirow[t]{2}{*}{ Age } & $\leq 35$ & 84 & $45.9 \%$ & 123 & $60.9 \%$ & 207 & $53.8 \%$ & $.003^{*}$ \\
\hline & $>35$ & 99 & $54.1 \%$ & 79 & $39.1 \%$ & 178 & $46.2 \%$ & \\
\hline \multirow[t]{2}{*}{ Sex } & Female & 103 & $56.3 \%$ & 114 & $56.4 \%$ & 217 & $56.4 \%$ & .98 \\
\hline & Male & 80 & $43.7 \%$ & 88 & $43.6 \%$ & 168 & $43.6 \%$ & \\
\hline \multirow[t]{2}{*}{ Nationality } & Non-Saudi & 103 & $56.3 \%$ & 100 & $49.5 \%$ & 203 & $52.7 \%$ & .183 \\
\hline & Saudi & 80 & $43.7 \%$ & 102 & $50.5 \%$ & 182 & $47.3 \%$ & \\
\hline \multirow[t]{2}{*}{ Specialty } & Family Medicine & 83 & $45.4 \%$ & 92 & $45.5 \%$ & 175 & $45.5 \%$ & .97 \\
\hline & General Practitioner & 100 & $54.6 \%$ & 110 & $54.5 \%$ & 210 & $54.5 \%$ & \\
\hline \multirow[t]{4}{*}{ Education Degree } & General Practitioner & 100 & $54.6 \%$ & 110 & $54.5 \%$ & 210 & $54.5 \%$ & .12 \\
\hline & Resident & 46 & $25.1 \%$ & 61 & $30.2 \%$ & 107 & $27.8 \%$ & \\
\hline & Register & 36 & $19.7 \%$ & 26 & $12.9 \%$ & 62 & $16.1 \%$ & \\
\hline & Consultant & 1 & $0.5 \%$ & 5 & $2.5 \%$ & 6 & $1.6 \%$ & \\
\hline \multirow[t]{4}{*}{ Years of Practice } & $0-5$ & 61 & $33.3 \%$ & 92 & $45.5 \%$ & 153 & $39.7 \%$ & $.006^{*}$ \\
\hline & $6-10$ & 33 & $18.0 \%$ & 42 & $20.8 \%$ & 75 & $19.5 \%$ & \\
\hline & $11-15$ & 38 & $20.8 \%$ & 39 & $19.3 \%$ & 77 & $20.0 \%$ & \\
\hline & $>15$ & 51 & $27.9 \%$ & 29 & $14.4 \%$ & 80 & $20.8 \%$ & \\
\hline
\end{tabular}

*significant at $p<.05$

these physicians were consultants $(p<.001)$. Additionally, the majority $(84.2 \%)$ of respondents reported that they would advise and counsel patients with diabetes regarding the importance of recommended vaccines before they travelled. More than half (59.0\%) were aware of travel safety recommendations for patients with diabetes. A significantly higher percentage of these physicians were general practitioners $(p<.001)$. Approximately two-thirds (67.8\%) reported that they did not feel confident about how to adjust insulin doses for patients travelling across several time zones. A significantly higher percentage of these physicians were general practitioners $(p<001)$. A total of 219 (56.9\%) participants stated that patients mostly asked

Table 6 Practitioners' practices towards pre-travel counselling and their relation to their degree of education

\begin{tabular}{|c|c|c|c|c|c|c|}
\hline & \multicolumn{6}{|c|}{ Education degree } \\
\hline & \multirow{2}{*}{$\begin{array}{l}\text { GP } \\
N(\%)\end{array}$} & \multirow{2}{*}{$\begin{array}{l}\text { Resident } \\
\mathrm{N}(\%)\end{array}$} & \multirow{2}{*}{$\begin{array}{l}\text { Register } \\
\text { N (\%) }\end{array}$} & \multirow{2}{*}{$\begin{array}{l}\text { Consultant } \\
\mathrm{N}(\%)\end{array}$} & \multicolumn{2}{|l|}{ Total } \\
\hline & & & & & $\mathrm{N}(\%)$ & $\begin{array}{l}P \\
\text { value }\end{array}$ \\
\hline $\begin{array}{l}\text { 1- Estimated number of patients with diabetes that visit clinic per week for any } \\
\text { reason } 20-40\end{array}$ & $\begin{array}{l}100 \\
(47.6 \%)\end{array}$ & $47(43.9)$ & $\begin{array}{l}28 \\
(45.2 \%)\end{array}$ & $4(66.7 \%)$ & $\begin{array}{l}179 \\
(46.5 \%)\end{array}$ & .77 \\
\hline $\begin{array}{l}\text { 2- Estimated number of patients with diabetes that ask for advice before his/her trip } \\
\text { per month } 1-10\end{array}$ & $\begin{array}{l}128 \\
(61.0 \%)\end{array}$ & $\begin{array}{l}34 \\
(31.8 \%)\end{array}$ & $\begin{array}{l}38 \\
(61.3 \%)\end{array}$ & $5(83.3 \%)$ & $\begin{array}{l}205 \\
(53.2 \%)\end{array}$ & $<.001^{*}$ \\
\hline 3- Counseled a patient with diabetes before traveling, it take about 5-15 min & $\begin{array}{l}145 \\
(69.0 \%)\end{array}$ & $\begin{array}{l}46 \\
(43.0 \%)\end{array}$ & $\begin{array}{l}34 \\
(54.8 \%)\end{array}$ & $5(83.3 \%)$ & $\begin{array}{l}230 \\
(59.7 \%)\end{array}$ & $<.001^{*}$ \\
\hline $\begin{array}{l}\text { 4- I advise and counsel patient with diabetes regarding the importance of vaccines } \\
\text { before travel }\end{array}$ & $\begin{array}{l}174 \\
(82.9 \%)\end{array}$ & $\begin{array}{l}86 \\
(80.4 \%)\end{array}$ & $\begin{array}{l}58 \\
(93.5 \%)\end{array}$ & $6(100 \%)$ & $\begin{array}{l}324 \\
(84.2 \%)\end{array}$ & .08 \\
\hline $\begin{array}{l}\text { 5- I face patients with diabetes who are trying to avoid travel because of their } \\
\text { illness }\end{array}$ & $\begin{array}{l}50 \\
(23.8 \%)\end{array}$ & $\begin{array}{l}22 \\
(20.6 \%)\end{array}$ & $\begin{array}{l}14 \\
(22.6 \%)\end{array}$ & $2(33.3 \%)$ & $\begin{array}{l}88 \\
(22.9 \%)\end{array}$ & .85 \\
\hline 6- I am aware of travel safety recommendations for patients with diabetes & $\begin{array}{l}143 \\
(68.1 \%)\end{array}$ & $\begin{array}{l}34 \\
(31.8 \%)\end{array}$ & $\begin{array}{l}46 \\
(74.2 \%)\end{array}$ & $4(66.7 \%)$ & $\begin{array}{l}227 \\
(59.0 \%)\end{array}$ & $<.001^{*}$ \\
\hline $\begin{array}{l}\text { 7- I don't feel confident about how to adjust insulin dose for patients who travel } \\
\text { across several time zones }\end{array}$ & $\begin{array}{l}123 \\
(58.6 \%)\end{array}$ & $\begin{array}{l}97 \\
(90.7 \%)\end{array}$ & $\begin{array}{l}38 \\
(61.3 \%)\end{array}$ & $3(50.0 \%)$ & $\begin{array}{l}261 \\
(67.8 \%)\end{array}$ & $<.001^{*}$ \\
\hline
\end{tabular}

*significant at $p<.05$ 
about diabetes IDs, vaccinations, prescriptions, and medication adjustments.

The mean ranks of knowledge scores were significantly higher among physicians who were older than 35 years of age, were female, were non-Saudi, were general practitioners, and were at the registrar rank $(p<.05)$. Similarly, the practice score was significantly higher among physicians who were older than 35 years, were female, were non-Saudi, were general practitioners, and were consultants. However, the mean rank of the attitudes score was significantly higher among physicians aged 35 or younger $(p=.038)$, as demonstrated in Table 7.

The comparison of the three scores among the studied participants revealed a significantly higher knowledge score, followed by the attitudes score and the practice score (mean ranks were 2.54, 2.19 and 1.27, respectively), as shown in Table 8.

Table 9 illustrates a significant association between knowledge and practice scores $(p<.001)$, while the attitudes score did not show a significant relationship $(p>.05)$.

\section{Discussion}

To our knowledge, this study was the first to assess the knowledge, attitudes and practices of general health care providers regarding the pre-travel counselling of patients with diabetes in Saudi Arabia and the Middle East at large. It has demonstrated essential findings. First, this study showed that more than half $(57.9 \%)$ of the participants had poor knowledge scores. Second, more than half $(52.5 \%)$ of participants had agreement attitudes, while $183(47.5 \%)$ showed disagreement attitudes towards the importance of pre-travel counselling for patients with diabetes. Third, the majority $(62.6 \%)$ of the participants had low practice scores.

Travel health advice for patients with diabetes can be complex. Understanding the demographic features and travel-associated risk factors is important. While most participants identified the importance of pre-travel counselling of patients with diabetes, we found some important knowledge gaps. Participants were generally able to clinically advise patients with diabetes that they should to carry medicines and carbohydrate-rich snacks in easily accessible bags while travelling.

While the majority of participants in our study did not know that travelling across more than five time zones and in hot or cold climates affected insulin dose and frequency. Few participants knew that patients with diabetes travelling to the east region may need to increase their insulin dose, while those travelling to the west region may need to decrease their insulin dose. Similar to our findings, in a study by Gill and Redmond [6], investigators sent questionnaires to 160 physicians and asked how they were advising patients on insulin adjustments while traveling. They received questionnaires back from 60 (37\%) physicians. They study showed that advice was being given by the majority of these clinics with only $3 \%$ not giving any specific advice. Unfortunately, $21 \%$ of the advice provided was judged to be either unhelpful or potentially harmful.

Likewise, Piotte et al. [1] assessed the level of specific knowledge among primary care providers in eastern France regarding health advice, vaccinations and malaria prophylaxis. They concluded that the participants' high level of knowledge in travel medicine was mostly linked to their motivation to practice in this specialized discipline. This finding should be considered with respect to the provision of education programmes in our society.

Table 7 Comparison of demographic characteristics and KAP scores

\begin{tabular}{|c|c|c|c|c|c|c|c|}
\hline & & \multicolumn{2}{|c|}{ Knowledge score } & \multicolumn{2}{|c|}{ Attitudes score } & \multicolumn{2}{|c|}{ Practice score } \\
\hline & & Mean rank & $P$ value & Mean rank & $P$ value & Mean rank & $P$ value \\
\hline \multirow[t]{2}{*}{ Age } & $<=35$ & 166.56 & $<.001^{*}$ & 203.45 & $.038^{*}$ & 160.61 & $<.001^{*}$ \\
\hline & $>35$ & 223.75 & & 180.84 & & 230.67 & \\
\hline \multirow[t]{2}{*}{ Sex } & Female & 208.59 & $.001^{*}$ & & .074 & 215.51 & $<.001^{*}$ \\
\hline & Male & 172.86 & & & & 163.92 & \\
\hline \multirow[t]{2}{*}{ Nationality } & Non-Saudi & 220.55 & $<.001^{*}$ & & .67 & 224.40 & $<.001^{*}$ \\
\hline & Saudi & 162.27 & & & & 157.98 & \\
\hline \multirow[t]{2}{*}{ Specialty } & Family Medicine & 175.16 & $.003^{*}$ & & .71 & 166.03 & $<.001^{*}$ \\
\hline & General Practitioner & 207.87 & & & & 215.48 & \\
\hline \multirow[t]{4}{*}{ Degree of Education } & General Practitioner & 207.87 & $<.001^{*}$ & & .28 & 215.48 & $<.001^{*}$ \\
\hline & Resident & 147.45 & & & & 134.77 & \\
\hline & Register & 223.16 & & & & 212.34 & \\
\hline & Consultant & 173.33 & & & & 244.50 & \\
\hline
\end{tabular}

*significant at $p<.05$ 
Table $\mathbf{8}$ Score summary of knowledge, attitudes, and practices among primary health care physicians towards pre-travel counselling

\begin{tabular}{|c|c|c|c|c|c|c|c|}
\hline Scores & & $\mathbf{N}$ & $\%$ & Minimum- Maximum & Median & IQR & Mean Ranks \\
\hline \multirow[t]{3}{*}{ Knowledge } & Good & 14 & $3.6 \%$ & $2-10$ & 5 & $4-6$ & 2.54 \\
\hline & Moderate & 148 & $38.4 \%$ & & & & \\
\hline & Poor & 223 & $57.9 \%$ & & & & \\
\hline \multirow[t]{2}{*}{ Attitude } & Disagree & 183 & $47.5 \%$ & $0-6$ & 5 & $4-6$ & 2.19 \\
\hline & Agree & 202 & $52.5 \%$ & & & & \\
\hline \multirow[t]{2}{*}{ Practice } & Good & 144 & $37.4 \%$ & $1-4$ & 3 & $2-4$ & 1.27 \\
\hline & Poor & 241 & $62.6 \%$ & & & & \\
\hline
\end{tabular}

Another study by Al-Hajri et al. [11] surveyed 76 PHC physicians in Qatar. The questionnaire included items assessing socio-demographic characteristics and knowledge and practices related to travel medicine before and after an educational symposium [11]. They detected significantly increased knowledge on the post-symposium questionnaire for most questions. This reflects the fact that the availability of extensive educational programs for healthcare providers will increase their awareness and knowledge.

Regarding the attitudes of participants towards pretravel counselling, our results showed that more than half of participants strongly agreed that Saudi Arabia lacks the practice of travel medicine, and two-thirds strongly agreed that our society lacks knowledge of the importance of travel medicine. As travel becomes more frequent in Saudi, pre-travel counselling and risk assessment are needed to understand travel-related risks and to better enable preparation for such activity. Therefore, our findings could promote the implementation of training programmes on travel medicine to cover the deficiencies detected and to provide sufficient information during pre-travel counselling.

With regard to the practice of pre-travel counselling, our results showed that approximately two-thirds of the participants, especially general practitioners, reported that they did not feel confident about how to adjust insulin doses for patients travelling across several time zones. This may be the reason that most provider characteristics were not associated with the knowledge of

Table 9 Association between knowledge and subjects' attitudes and practices towards pre-travel counselling

\begin{tabular}{|c|c|c|c|c|c|c|c|c|}
\hline & & \multicolumn{6}{|c|}{ Knowledge score } & \multirow[b]{3}{*}{$P$ value } \\
\hline & & \multicolumn{2}{|l|}{$\leq 5$} & \multicolumn{2}{|l|}{$>5$} & \multicolumn{2}{|c|}{ Total } & \\
\hline & & $\mathrm{N}$ & $\%$ & $\mathrm{~N}$ & $\%$ & $\mathrm{~N}$ & $\%$ & \\
\hline \multirow[t]{2}{*}{ Attitudes } & Disagree & 102 & $55.7 \%$ & 81 & $44.3 \%$ & 183 & $100.0 \%$ & .41 \\
\hline & Agree & 121 & $59.9 \%$ & 81 & $40.1 \%$ & 202 & $100.0 \%$ & \\
\hline \multirow[t]{2}{*}{ Practices } & Good & 56 & $38.9 \%$ & 88 & $61.1 \%$ & 144 & $100.0 \%$ & $<.001^{*}$ \\
\hline & Poor & 167 & $69.3 \%$ & 74 & $30.7 \%$ & 241 & $100.0 \%$ & \\
\hline
\end{tabular}

*significant at $p<.05$ guideline recommendations for travel health. Additionally, there is a lack of health travel programmes.

Similar to our findings, Kogelman et al. [12] compared the knowledge, attitudes and practices of US primary care providers and US travel medicine specialists. They demonstrated knowledge and practice deficits among practitioners offering travel medicine advice. Furthermore, they revealed that familiarity with travel-specific vaccines and knowledge scores based on brief pre-travel scenarios were higher among travel medicine specialists.

The provision of comprehensive pre-travel health advice is essential to reduce the incidence of travel-related morbidity. Studies from other countries found that primary care physicians are active in travel medicine [13]. In our study more than half $(84.2 \%)$ of the PHCP counselling patients with diabetes regarding the importance of vaccines before travel. This reflects the fact that the available vaccination schedules are better known.

In contrast to the study was done in Qatar, which reported that more than $50 \%$ did not offer travel health counselling for traveller [11].

A comparison of the knowledge, attitudes and practices scores among the studied participants revealed a significantly higher knowledge score, followed by the attitudes score and the practice score (mean ranks were 2.54, 2.19 and 1.27, respectively). Additionally, a significant positive correlation was detected between knowledge and practice scores. Improving the level of knowledge of PHC physicians directly affects their practices. Furthermore, the structure of pre-travel consultations should address the travellers' wishes, expectations, difficulties, experiences, and previous knowledge. Physicians should ask the traveller whether he or she understood the advice given. Finally, a booklet with additional advice and a website where patients can find health advice on their destination should be provided [14].

A limitation of this study is the use of a survey tool that has not undergone prior reliability and validity testing. In addition, the result of this study cannot be generalised to other populations in the country because KAP might be greatly influenced by socio-demographic factors of the population. More studies on the travel of 
Saudi's population with diabetes need to be performed, especially with the increasing affluence and diverse travel habits in the region.

\section{Conclusions}

The study has found a gap in the knowledge and practices of primary health care physicians regarding pretravel counselling for patients with type 2 diabetes. In addition, these deficiencies were more significant among physicians who were younger, male, and Saudi and who had a general practitioner specialty; in contrast, disagreement attitudes were significantly associated with being older and having more years of experience. Therefore, easily accessible travel medicine education programmes for Saudi PHC providers are needed to improve the management of travellers with diabetes.

\section{Abbreviations}

PHC: Primary health care; PHCCs: Primary health care centres; $\mathrm{MOH}$ : Ministry of health; PCPs: Primary care physicians; KAP: Knowledge, attitude, and practice

\section{Acknowledgements}

We would like to thank all the PHC physicians for their volunteering to participate in the study.

\section{Authors' contributions}

Rabia Khalid Alduraibi (RD) and Mohammed Ali Batais (MB) were responsible for the conception of the research idea and the study design. RD, MB, Turky $H$. Almigbal (TM), and Abdullah A. Alrasheed (AR) were responsible for the supervision, data collection, analysis, interpretation, and drafting of the manuscript. All authors read and approved the final manuscript.

\section{Funding}

There was no funding for this study.

\section{Availability of data and materials}

The data generated or analyzed during this study were included in this published article.

\section{Ethics approval and consent to participate}

The study was approved by the Institutional Review Board, College of Medicine, King Saud University (no. E-18-0488), Riyadh, Saudi Arabia. Each participant was informed in detail, and his/her consent was obtained before the data collection.

All participants provided informed written consent before the completion of the questionnaires

\section{Consent for publication}

All participants provided a written informed consent to publish this study.

\section{Competing interests}

The authors have declared no competing interests.

\section{Author details}

${ }^{1}$ King Fahad Specialist Hospital, Buraydah, Saudi Arabia. ${ }^{2}$ Department of Family and Community Medicine, King Khalid University Hospital, Box 2925, Riyadh, PO 11461, Saudi Arabia. ${ }^{3}$ Department of Family and Community Medicine, King Saud University, Riyadh, Saudi Arabia.
Received: 24 February 2020 Accepted: 15 September 2020

Published online: 24 September 2020

\section{References}

1. Piotte E, Bellanger AP, Piton G, et al. Pre-travel consultation: evaluation of primary care physician practice in the Franche-comté region. J Travel Med. 2013;20:221-7.

2. Lengyel I, Felkai P. Pre-travel advice and patient education of Hungarian travellers. Orv Hetil. 2018:159:357-62.

3. Steffen R. 3. Travel medicine-prevention based on epidemiological data. Trans R Soc Trop Med Hyg. 1991;85:156-62.

4. Burnett JCD. Long- and short-haul travel by air: issues for people with diabetes on insulin. J Travel Med. 2006;13:255-60.

5. Pinsker JE, Schoenberg BE, Garey C, et al. Perspectives on long-distance air travel with type 1 diabetes. Diabetes Technol Ther. 2017:19:744-8.

6. Gill GV, Redmond S. Insulin treatment, time-zones and air travel: a survey of current advice from british diabetic clinics. Diabet Med. 1993;10:764-7.

7. Paudel P, Raina C, Zwar N, et al. Risk activities and pre-travel health seeking practices of notified cases of imported infectious diseases in Australia. J Travel Med. 2017;24. https://doi.org/10.1093/jtm/tax044.

8. Ghosh S, Bajaj S, Chatterjee P, et al. Diabetes and travel. Int J Diabetes Dev Ctries. 2018:38:4-10.

9. Morteza I, Sadat HM, Hossein P. Travel guidance for people with diabetes. Int J Travel Med Global Health. 2015:3:149-54

10. Elkins BE, True MW, Ramos RG, Cranston MM. How do you get there with diabetes? Results of a survey of diabetic travelers. J Tourism Hospitality. 2014;3. https://doi.org/10.4172/2167-0269.1000128.

11. Al-Hajri M, Bener A, Balbaid O, Eljack E. Knowledge and practice of travel medicine among primary health care physicians in Qatar. Southeast Asian J Trop Med Public Health. 2011;42:1546-52.

12. Kogelman L, Barnett ED, Chen LH, et al. Knowledge, attitudes, and practices of US practitioners who provide pre-travel advice. J Travel Med. 2014;21: 104-14.

13. Schunk $M$, Wachinger $W$, Nothdurft HD. Vaccination status and prophylactic measures of travelers from Germany to subtropical and tropical areas: results of an airport survey. J Travel Med. 2001;8(5):260.

14. Marchand C, Merrina F, Gagnayre R, Bouchaud O. A descriptive study of advising practices during travel health consultations in France. J Travel Med. 2017:24. https://doi.org/10.1093/jtm/tax042.

\section{Publisher's Note}

Springer Nature remains neutral with regard to jurisdictional claims in published maps and institutional affiliations.

\footnotetext{
Ready to submit your research? Choose BMC and benefit from:

- fast, convenient online submission

- thorough peer review by experienced researchers in your field

- rapid publication on acceptance

- support for research data, including large and complex data types

- gold Open Access which fosters wider collaboration and increased citations

- maximum visibility for your research: over $100 \mathrm{M}$ website views per year

At BMC, research is always in progress.

Learn more biomedcentral.com/submissions
} 